\title{
Simultaneous Hydrogen Production with the Degradation of Naphthalene in Seawater Using Solar Light-Responsive Carbon-Modified (CM)-n-TiO $\mathrm{T}_{2}$ Photocatalyst
}

\author{
Yasser A. Shaban ${ }^{1,2}$ \\ ${ }^{1}$ Marine Chemistry Department, Faculty of Marine Sciences, King Abdulaziz University, Jeddah, KSA \\ ${ }^{2}$ National Institute of Oceanography \& Fisheries, Qayet Bay, Alexandria, Egypt \\ Email: yasrsh@yahoo.com
}

Received July 21, 2013; revised August 15, 2013; accepted August 21, 2013

Copyright (C) 2013 Yasser A. Shaban. This is an open access article distributed under the Creative Commons Attribution License, which permits unrestricted use, distribution, and reproduction in any medium, provided the original work is properly cited.

\begin{abstract}
The simultaneous photocatalytic production of hydrogen and degradation of naphthalene in seawater was successfully achieved using carbon modified titanium oxide $\left(\mathrm{CM}-\mathrm{n}-\mathrm{TiO}_{2}\right)$ nanoparticles under natural sunlight illumination. Compared to unmodified titanium oxide $\left(\mathrm{n}-\mathrm{TiO}_{2}\right), \mathrm{CM}-\mathrm{n}-\mathrm{TiO}_{2}$ nanoparticles exhibited significantly higher photocatalytic efficiency. It is considered that carbon modification is responsible for the significant enhancement in the observed photoactivity. The experimental results indicated that the simultaneous production of hydrogen and degradation of naphthalene was favorable at $\mathrm{pH} 8$ and optimal catalyst dose of $1.0 \mathrm{~g} \cdot \mathrm{L}^{-1}$. The solar photocatalytic degradation of naphthalene in seawater using $\mathrm{CM}-\mathrm{n}-\mathrm{TiO}_{2}$ successfully fitted using Langmuir-Hinshelwood model, and can be described by pseudo-first order kinetic model.
\end{abstract}

Keywords: Photocatalysis; Titanium Oxide; Carbon Modification; Hydrogen Production; Naphthalene

\section{Introduction}

Photocatalysis on semiconductor surfaces has attracted considerable attention in recent years as a potential means for water splitting to produce hydrogen [1-8], and mineralization of organic pollutants present in water and wastewater [9-18]. Among many semiconductor oxides, titanium dioxide $\left(\mathrm{n}-\mathrm{TiO}_{2}\right)$ has been proven to be the most promising semiconductor due to its optical and electronic properties, low cost, high level of photocatalytic activity, chemical stability and non-toxicity. However, its utilization in the solar light is hampered by the fact that it is a UV absorber. Its wide band gap $(3.0-3.2 \mathrm{eV})$ limits its photoresponse in the ultraviolet region which is only a small fraction $(\sim 5 \%)$. Therefore, several attempts were made to extend its optical response to the visible spectral range by doping with transition metal $[19,20]$, nitrogen $[21,22]$, and sulfur [23]. Recently, it has been reported that carbon modification of $n-\mathrm{TiO}_{2}$ lowered its bandgap energy to $2.32 \mathrm{eV}$, and thereby exhibited higher photoresponse [3].

The principle of photocatalysis on titanium dioxide semiconductor is based on the conversion of photon energy to chemical energy. The elementary mechanism of this process includes a number of steps, which have been exhaustively described in the literature [24,25]. Illumination of $\mathrm{TiO}_{2}$ by light with energy $(\mathrm{h} v)$ greater than or equal to the bandgap energy $\left(\mathrm{E}_{\mathrm{g}}\right)$ of $\mathrm{TiO}_{2}$ elevates electron in the valence band (VB) to the conduction band $(\mathrm{CB})$, and a positive hole is formed in the valence band (Equation (1)). The conduction band electron $\left(e_{c b}^{-}\right)$is strongly reducing, and the valence band hole $\left(h_{v b}^{+}\right)$is strongly oxidizing. At the external $\mathrm{TiO}_{2}$ surface, the positive hole and the excited electron can take part in redox reactions with adsorbed groups.

$$
\mathrm{TiO}_{2}+\mathrm{h} v \rightarrow e_{c b}^{-}+h_{v b}^{+}
$$

The photoinduced production of hydrogen from water is attained by photogenerated electrons $\left(e_{c b}^{-}\right)$, provided that their energy is sufficient to reduce protons toward hydrogen molecules (Equation (3)). To achieve this process, the $\mathrm{CB}$ level should be more negative than hydrogen production level $\left(\mathrm{E}_{\mathrm{H}_{2} / \mathrm{H}_{2} \mathrm{O}}\right)$ while the $\mathrm{VB}$ should be more positive than water oxidation level $\left(\mathrm{E}_{\mathrm{O}_{2} / \mathrm{H}_{2} \mathrm{O}}\right)$ for efficient oxygen production from water by photocatalysis.

$$
2 h_{v b}^{+}+\mathrm{H}_{2} \mathrm{O}(1) \rightarrow 1 / 2 \mathrm{O}_{2}+2 \mathrm{H}^{+}
$$




$$
2 \mathrm{H}^{+}+2 e_{c b}^{-} \rightarrow \mathrm{H}_{2}(\mathrm{~g})
$$

One of the major disadvantages of semiconductor photocatalytic system is that, the photo-generated electrons and holes can recombine in bulk or on surface of the semiconductor within a very short time, resulting in reduction in the photocatalytic efficiency. To resolve this problem, electron donors (sacrificial reagents or hole scavengers) were added to react irreversibly with the photogenerated VB holes $\left(h_{v b}^{+}\right)$, thereby suppressing the electronhole recombination [26,27]. If this sacrificial agent is a pollutant present in water or wastewater, the positive hole $\left(h_{v b}^{+}\right)$would oxidize either pollutant directly (Equation (4)) or water to produce $\mathrm{OH}$ radical (Equation (5)). Consequently, enhancement of the $\mathrm{H}_{2}$ production rate with simultaneous degradation of the organic substrate can be obtained. A simplified diagram illustrating the simultaneous photocatalytic production of hydrogen and degradation of organic compound using $\mathrm{TiO}_{2}$ under illumination of light is presented in Figure 1.

$$
\begin{gathered}
h_{v b}^{+}+\text {Organic pollutants } \rightarrow \mathrm{CO}_{2}(\mathrm{~g}) \\
h_{v b}^{+}+\mathrm{H}_{2} \mathrm{O}(1) \rightarrow \cdot \mathrm{OH}+\mathrm{H}^{+} \\
\cdot \mathrm{OH}+\text { Organic pollutant } \rightarrow \mathrm{CO}_{2}(\mathrm{~g})
\end{gathered}
$$

The vast majority of researches on $\mathrm{TiO}_{2}$ photocatalysis have focused on a single process; either the photodegradation of pollutants or hydrogen generation under illumination of artificial UV light or simulated sunlight. Despite the importance of seawater as it has been considered to supplement the limited sources of water available for drinking, as well as for the production of hydrogen energy [28], most of the studies on photocatalytic hydrogen production and degradation of pollutants have been performed using pure water. Based on the previous considerations, the present study focused on the synthesis of visible light active carbon-modified (CM)-n- $\mathrm{TiO}_{2}$ nanoparticles that is capable of harvesting the maximum solar light in the visible region. The simultaneous production of hydrogen and degradation of naphthalene, as a

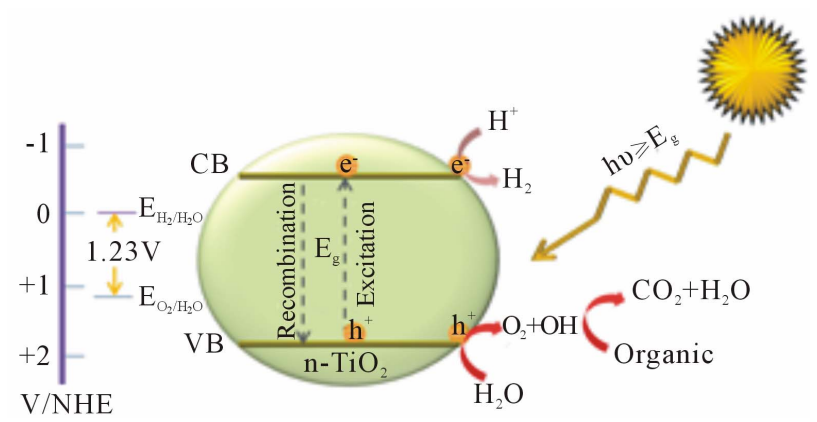

Figure 1. A simplified diagram of the simultaneous photocatalytic production of hydrogen and degradation of organic compound using $\mathrm{TiO}_{2}$ under illumination of light. sacrificial agent, in natural seawater was investigated using the synthesized photocatalyst under illumination of real sunlight. The effects of photocatalyst loading, naphthalene concentration, and $\mathrm{pH}$ on the photocatalytic performance were also studied.

\section{Experimental}

\subsection{Synthesis and Characterization of $\mathbf{n}-\mathrm{TiO}_{2}$ and $\mathrm{CM}-\mathrm{n}-\mathrm{TiO}_{2}$ Nanoparticles}

Regular (unmodified) titanium dioxide $\left(\mathrm{n}-\mathrm{TiO}_{2}\right)$ nanoparticles were synthesized by hydrolysis and oxidation of titanium trichloride $\left(\mathrm{TiCl}_{3} 12 \%\right.$ in hydrochloric acid $(5 \%$ - 12\%), Sigma-Aldrich) in an aqueous medium. Visible light active carbon modified titanium dioxide (CM-n$\mathrm{TiO}_{2}$ ) nanoparticals were synthesized by a sol-gel method using titanium butoxide ( $\mathrm{Ti}\left[\mathrm{O}\left(\mathrm{CH}_{2}\right)_{3} \mathrm{CH}_{3}\right]_{4}$, Fluka, 97\%), a carbon-containing precursor, as a molecular precursor of $\mathrm{TiO}_{2}$ as well as a carbon source. Details on the procedures used for catalysts preparation and characterization can be found elsewhere [18].

\subsection{Photocatalytic Experiments}

All solar photocatalytic experiments were carried out at the Faculty of Marine sciences, Obhur, Jeddah, KSA, in the daytime between 11:00 am to 15:00 pm, during MayJune, 2013. Natural seawater samples were collected from Sharm Obhur, Jeddah, KSA. Before spiking with different concentrations of naphthalene, seawater samples were passed through Whatman GFC to remove any solid particles. Experimental set up consisted of a magnetically stirred $500 \mathrm{~mL}$ top-covered Pyrex glass photoreactor loaded with the seawater solution containing different concentrations of naphthalene ranging from 5 to $20 \mathrm{ppm}$, then the synthesized photocatalyst $\left(\mathrm{n}-\mathrm{TiO}_{2}\right.$ or $\mathrm{CM}-\mathrm{n}-\mathrm{TiO}_{2}$ ) was added. Prior to the reaction, the mixture was purged with $\mathrm{N}_{2}$ gas $(99.999 \%)$ to remove any atmospheric oxygen. The photocatalytic reactor was then directly exposed to natural sunlight. The average solar intensity was about $1200 \mathrm{~W} \cdot \mathrm{m}^{-2}$, measured by Field Scout Light Sensor Reader (Spectrum Technologies, Inc.) equipped with 3670i Silicon Pyranometer Sensor. The amount of photogenerated hydrogen was analyzed using a gas chromatograph (Bruker, GC-450), equipped with a thermal conductivity detector (TCD), high purity Ar (99.999\%) was used as a carrier gas. Analysis of naphthalene content in solution has been achieved with the use of a Shimadzu UV-VIS Spectrophotometer (Model PharmaSpec UV-1700). Prior to analysis, aliquots of treated seawater samples were regularly withdrawn from the reactor and centrifuged immediately to remove the catalyst. The supernatant was then immediately analyzed for its naphthalene content. The photodegradation efficiency $(\eta)$ was calculated from the decrease of the absorbance of naph- 
thalene at its maximum absorption wavelength $(275 \mathrm{~nm})$ as follows:

$$
\eta=\left[\left(\mathrm{C}_{\mathrm{o}}-\mathrm{C}_{\mathrm{t}}\right) / \mathrm{C}_{\mathrm{o}}\right] \times 100
$$

where $\mathrm{C}_{0}$ represents the initial concentration of the naphthalene and $\mathrm{C}_{\mathrm{t}}$ represents the concentration of naphthalene at solar light irradiation time $(\mathrm{t})$.

\section{Results and Discussion}

\subsection{Photocatalytic Activity of $\mathrm{n}-\mathrm{TiO}_{2}$ and CM-n-TiO}

In order to examine the photocatalytic efficiency of CM$\mathrm{n}-\mathrm{TiO}_{2}$, comparison with unmodified $\mathrm{n}-\mathrm{TiO}_{2}$ was performed under the same experimental conditions. It is clearly observed that the photocatalytic efficiency of $\mathrm{CM}-\mathrm{n}-\mathrm{TiO}_{2}$ towards the simultaneous photocatalytic production of hydrogen and degradation of naphthalene (10 $\mathrm{ppm}$ ) in seawater under illumination of natural sunlight is much higher than that of $\mathrm{n}-\mathrm{TiO}_{2}$ (Figure 2). The enhanced photocatalytic activity of carbon modified CM-n-TiO nanoparticles can be attributed to carbon modification of $\mathrm{TiO}_{2}[3,5-8,17,18]$.

\subsection{Effect of Solution $\mathrm{pH}$}

It is known that the $\mathrm{pH}$ of the solution is a key parameter in the photocatalytic reactions, it can directly influence the surface charge of the semiconductor, thereby affecting the interfacial electron transfer and the photoredox process [29]. The possible functional groups on $\mathrm{TiO}_{2}$ surface in water are $\mathrm{TiOH}_{2}^{+}, \mathrm{TiOH}$, and $\mathrm{TiO}^{-}$. The point of zero charge $\left(\mathrm{pH}_{\mathrm{pzc}}\right)$ of $\mathrm{TiO}_{2}$ is an important factor determining the distribution of the surface groups.

When $\mathrm{pH}>\mathrm{pH}_{\mathrm{pzc}}$, the surface of $\mathrm{TiO}_{2}$ is negatively charged with the species $\mathrm{TiO}^{-}$(Equation (8)), and positively charged with the species $\mathrm{TiOH}_{2}^{+}$at $\mathrm{pH}<\mathrm{pH}_{\mathrm{pzc}}$ (Equation (9)).

$$
\begin{gathered}
\mathrm{TiOH}+\mathrm{OH}^{-} \rightarrow \mathrm{TiO}^{-}+\mathrm{H}_{2} \mathrm{O} \\
\mathrm{TiOH}+\mathrm{H}^{+} \rightarrow \mathrm{TiOH}_{2}^{+}
\end{gathered}
$$

The role of $\mathrm{pH}$ in the photocatalytic production of $\mathrm{H}_{2}$ and degradation of naphthalene in seawater under illumination of natural sunlight using $\mathrm{CM}-\mathrm{n}-\mathrm{TiO}_{2}$ was studied by keeping all other experimental conditions constant and varying the initial $\mathrm{pH}$ of the solution from 3 to 9 . As can be seen in Figure 3, both the production of $\mathrm{H}_{2}$ and degradation of naphthalene rapidly increased with increasing the $\mathrm{pH}$ from 3 to 8 , beyond which the photocatalytic production of $\mathrm{H}_{2}$ and degradation of naphthalene started to decrease, indicating an optimum $\mathrm{pH}$ of approximately 8 for best performance. As the high redox potentials of Equation (3) in acidic condition, the formation of hydroxyl radicals will be thermodynamically un-

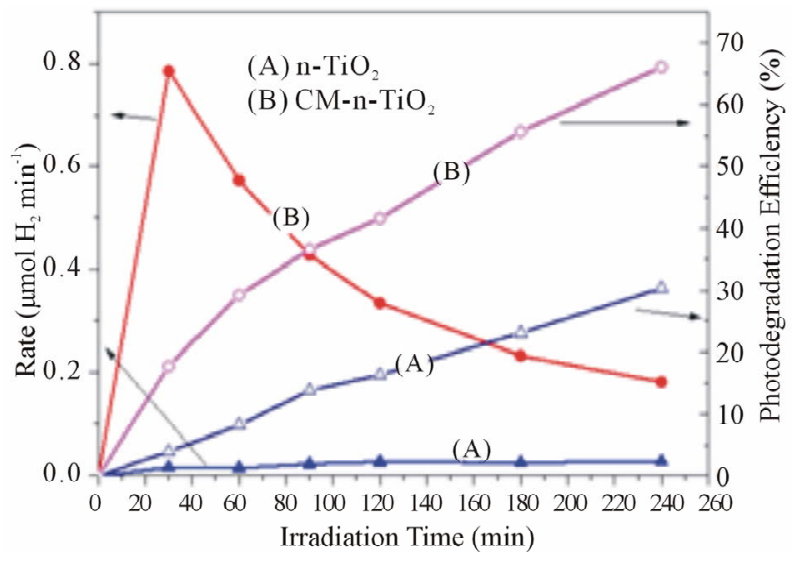

Figure 2. Simultaneous degradation of naphthalene (10 ppm) and production of hydrogen in the presence of $n-\mathrm{TiO}_{2}$ and $\mathrm{CM}-\mathrm{n}-\mathrm{TiO}_{2}$ under illumination of natural sunlight.

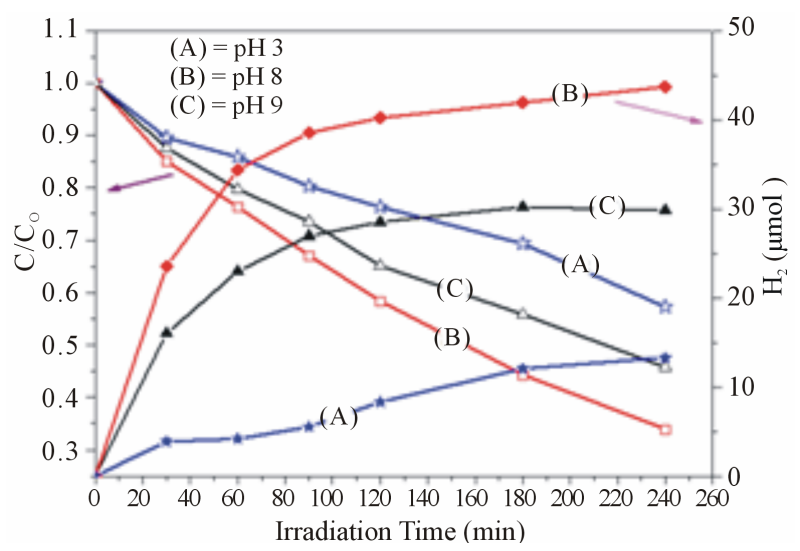

Figure 3. Effect of $\mathrm{pH}$ on the simultaneous degradation of naphthalene (10 $\mathrm{ppm})$ and production of hydrogen in the presence of $1.0 \mathrm{~g} \cdot \mathrm{L}^{-1}$ of $\mathrm{CM}-\mathrm{n}-\mathrm{TiO}_{2}$ under illumination of natural sunlight.

favorable [30]. As a result, the formation of hydroxyl radicals increased with an increase in $\mathrm{pH}$ from 3 to 8 , resulting in an increased photocatalytic efficiency. At $\mathrm{pH}$ higher than 8 , the formation of carbonate ions is favorable which are effective scavengers of hydroxyl ions and can reduce the efficiency of photodcatalytic process [31, 32].

\subsection{Effect of Catalyst Dose}

The influence of $\mathrm{CM}-\mathrm{n}-\mathrm{TiO}_{2}$ dose on the photocatalytic production of $\mathrm{H}_{2}$ and degradation of naphthalene (10 $\mathrm{ppm}$ ) in seawater under illumination of sunlight was investigated at the optimal $\mathrm{pH}$ value $(\mathrm{pH} 8)$ to ensure maximum absorption of efficient solar light photons as well as to avoid an ineffective excess amount of catalyst (Figure 4).

Both the photocatalytic degradation rate of naphthalene and the production of $\mathrm{H}_{2}$ increased with the increase in catalyst dose from 0.5 to $1.0 \mathrm{~g} \cdot \mathrm{L}^{-1}$. The increase in 


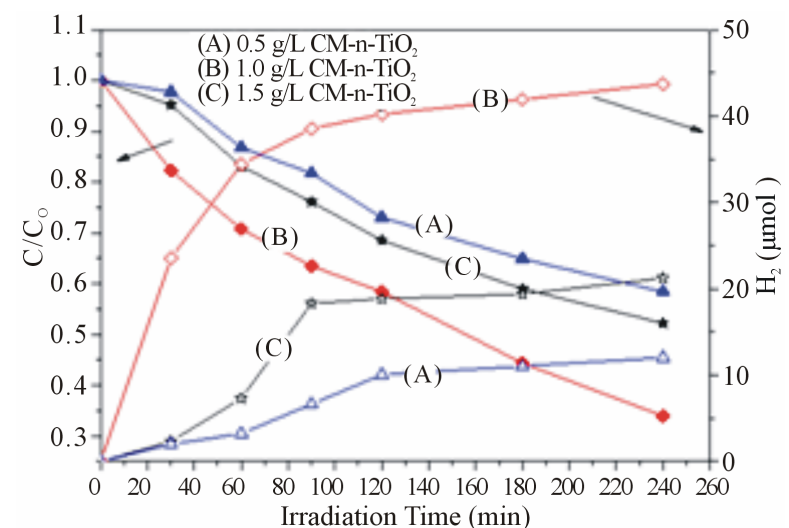

Figure 4. Effect of $\mathrm{CM}-\mathrm{n}-\mathrm{TiO}_{2}$ dose on the simultaneous degradation of naphthalene $(10 \mathrm{ppm})$ and production of hydrogen under illumination of natural sunlight.

catalyst amount actually increases the number of active sites on the photocatalyst surface thus causing an increase in the number of $e_{c b}^{-}$and $h_{v b}^{+}$which can take part in photocatalytic processes. Further increase in the catalyst loading to $1.5 \mathrm{~g} \cdot \mathrm{L}^{-1}$ slightly decreased the photocatalytic efficiency. At catalyst loading beyond the optimum, the tendency toward particles aggregation increases, resulting in a reduction in surface area available for light absorption and hence a drop in photocatalytic degradation rate [33]. Additionally, the increase of the turbidity of the suspension reduces light penetration due to the enhancement of light scattering; the result is the decrease of the number of activated sites on the $\mathrm{TiO}_{2}$ surface and shrinking of the effective photoactivated volume of suspension. The interplay of these two processes resulted in a reduced performance of photocatalytic activity with the overloaded catalyst [34,35]. In this study, the dosage of $1.0 \mathrm{~g} \cdot \mathrm{L}^{-1}$ of $\mathrm{CM}-\mathrm{n}-\mathrm{TiO}_{2}$ can be considered as the optimal catalyst loading.

\subsection{Effect of Initial Naphthalene Concentration}

The initial concentration of naphthalene is an important factor which needs to be taken into account. The effect of the initial naphthalene concentration on its photodegradation rate and the photocatalytic production of $\mathrm{H}_{2}$ was investigated over the range of 5 to $20 \mathrm{ppm}$ at the optimal conditions of $\mathrm{pH} 8$ and $1.0 \mathrm{~g} \cdot \mathrm{L}^{-1}$ of $\mathrm{CM}-\mathrm{n}-\mathrm{TiO}_{2}$ (Figure 5). Both the photoinduced production of $\mathrm{H}_{2}$ (Figure 5(a)) and degradation rate of naphthalene (Figure 5(b)) rapidly increased with the increase in naphthalene concentration from 5 to $10 \mathrm{ppm}$. Further increase of naphthalene concentration to $20 \mathrm{ppm}$, resulted in a remarkable decrease in the rate of degradation of naphthalene as well as the production of $\mathrm{H}_{2}$.

This can be explained by the saturation of the limited number of accessible active sites on the photocatalyst surface and/or deactivation of the active sites of the catalyst. Several studies have reported that high organic

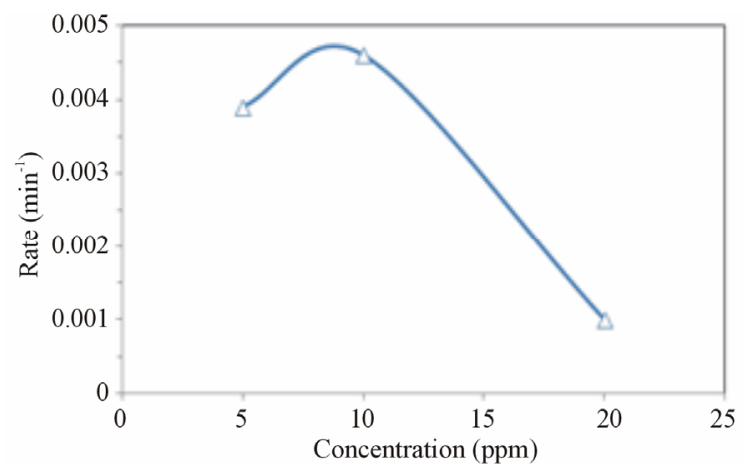

(a)

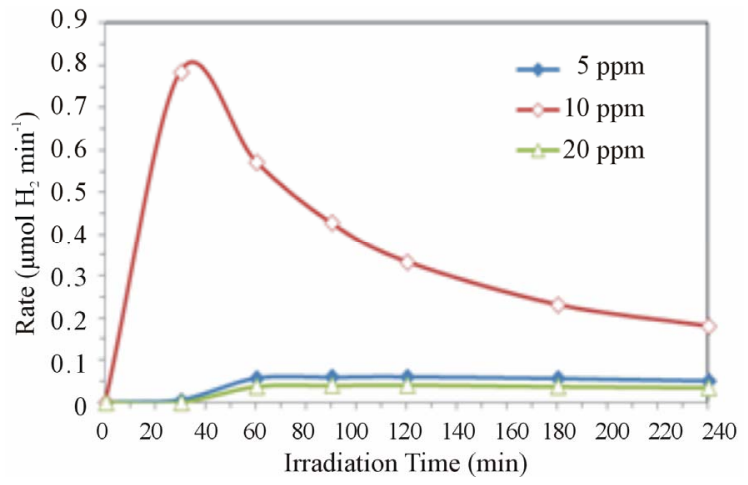

(b)

Figure 5. (a) Rate of photodegradation of naphthalene as a function of naphthalene concentration at the optimal conditions of $\mathrm{pH} 8$ and $1.0 \mathrm{~g} \cdot \mathrm{L}^{-1}$ of $\mathrm{CM}^{-n}-\mathrm{TiO}_{2}$; (b) Rate of hydrogen evolution as a function of solar irradiation time at the optimal conditions of $\mathrm{pH} 8$ and $1.0 \mathrm{~g} \cdot \mathrm{L}^{-1}$ of $\mathrm{CM}-\mathrm{n}-\mathrm{TiO}_{2}$ in the presence of 5,10 , and $20 \mathrm{ppm}$ of naphthalene.

substrate loadings induce the formation of intermediates that could be adsorbed onto the catalyst surface and deactivate the active sites [36,37].

\subsection{Kinetics of Photodegradation}

To study the kinetics of photocatalytic degradation of naphthalene in seawater using $\mathrm{CM}-\mathrm{n}-\mathrm{TiO}_{2}$, Langmuir-Hinshelwood (L-H) model was applied. L-H model basically relates the degradation rate $(r)$ and reactant concentration in water at time $t(C)$, which is expressed as follows:

$$
r=-\frac{d c}{d t}=\frac{k_{r} K_{a d}}{1+K_{a d} C}
$$

where $k_{r}$ is the rate constant and $K_{a d}$ is the adsorption equilibrium constant [38-41]. When the adsorption is relatively weak and/or the reactant concentration is low, equation (10) can be simplified to the pseudo-first order kinetics with an apparent first-order rate constant $k_{a p p}$ :

$$
\ln \left(\frac{C_{o}}{C}\right)=k_{r} K_{a d} t=k_{a p p} t
$$

where $C_{\mathrm{o}}$ is the initial concentration. Figure 6 shows the plot of $\ln \left(C_{o} / C\right)$ versus illumination time for the 


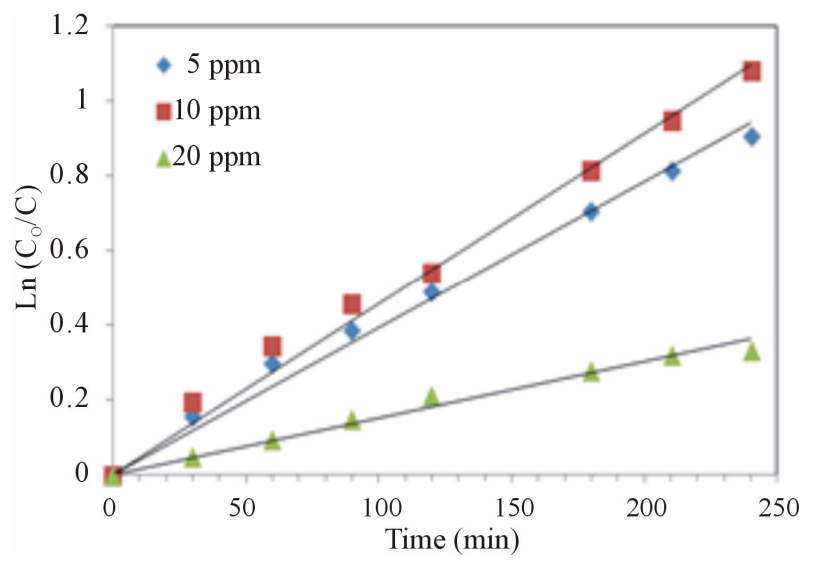

Figure 6. Plot of $\ln \left(\mathrm{C}_{\mathrm{o}} / \mathrm{C}\right)$ versus illumination time for the photocatalytic degradation of naphthalene $(5-20 \mathrm{ppm})$ in seawater under natural sunlight illumination using $1.0 \mathrm{~g} \cdot \mathrm{L}^{-1}$ CM-n-TiO .

photocatalytic degradation of naphthalene (5 - $20 \mathrm{ppm})$ in seawater under natural sunlight illumination at the optimal conditions of $\mathrm{pH} 8$ and $1.0 \mathrm{~g} \cdot \mathrm{L}^{-1}$ of $\mathrm{CM}-\mathrm{n}-\mathrm{TiO}_{2}$. The linearity of the plot confirmed that the photocatalytic degradation of naphthalene using $\mathrm{CM}-\mathrm{n}-\mathrm{TiO}_{2}$ follows the $\mathrm{L}-\mathrm{H}$ model, and can be described by pseudo-first order kinetics.

\section{Conclusion}

The photocatalytic production of hydrogen accompanied by the simultaneous degradation of naphthalene in seawater was successfully achieved using carbon-modified (CM)-n- $\mathrm{TiO}_{2}$ nanoparticles under irradiation of natural sunlight. CM-n- $\mathrm{TiO}_{2}$ nanoparticles exhibited significantly enhanced photocatalytic efficiency compared to unmodified $\mathrm{n}-\mathrm{TiO}_{2}$. This observed enhancement in the photoactivity can be attributed to the carbon modification. The simultaneous production of hydrogen and degradation of naphthalene was favorable at $\mathrm{pH} 8$ and optimal catalyst dose of $1.0 \mathrm{~g} \cdot \mathrm{L}^{-1}$. The solar photocatalytic degradation of naphthalene in seawater using $\mathrm{CM}-\mathrm{n}-\mathrm{TiO}_{2}$ successfully fitted using Langmuir-Hinshelwood model, and can be described by pseudo-first order kinetic model.

\section{Acknowledgements}

The author is thankful to Mr. Mousa Al Zobidi for his valuable help in the experimental analysis.

\section{REFERENCES}

[1] A. Fujishima and K. Honda, "Electrochemical Photolysis of Water at a Semiconductor Electrode," Nature, Vol. 238, No. 5358, 1972, pp. 37-38.

[2] S. U. M. Khan and J. Akikusa, "Photoelectrochemical Splitting of Water at Nanocrystalline n- $\mathrm{Fe}_{2} \mathrm{O}_{3}$ Thin-Film Electrodes," The Journal of Physical Chemistry B, Vol.
103, No. 34, 1999, pp. 7184-7189. doi:10.1021/jp990066k

[3] S. U. M. Khan, M. Al-Shahry and W. B. Ingler Jr., "Efficient Photochemical Water Splitting by a Chemically Modified n-TiO 2 ," Science, Vol. 297, No. 5590, 2002, pp. 2243-2245. doi:10.1126/science.1075035

[4] S. K. Mohaputra, M. Mishra and V. K. Mahajan, "Design of a Highly Efficient Photoelectrolytic Cell for Hydrogen Generation by Water Splitting: Application of $\mathrm{TiO}_{2-\mathrm{x}} \mathrm{C}_{\mathrm{x}}$ Nanotubes as a Photoanode and $\mathrm{Pt} / \mathrm{TiO}_{2}$ Nanotubes as a Cathode," The Journal of Physical Chemistry C, Vol. 111, No. 24, 2007, pp. 8677-8685. doi:10.1021/jp071906v

[5] C. Xu, Y. A. Shaban, W. B. Ingler Jr. and S. U. M. Khan, "Nanotube Enhanced Photoresponse of Carbon Modified (CM)-n- $\mathrm{TiO}_{2}$ for Efficient Water Splitting," Solar Energy Materials Solar Cells, Vol. 91, No. 10, 2007, pp. 938943. doi:10.1016/j.solmat.2007.02.010

[6] Y. A. Shaban and S. U. M. Khan, "Visible Light Active Carbon Modified n- $\mathrm{TiO}_{2}$ for Efficient Hydrogen Production by Photoelectrochemical Splitting of Water," International Journal of Hydrogen Energy, Vol. 33, No. 4, 2008, pp. 1118-1126. doi:10.1016/j.ijhydene.2007.11.026

[7] Y. A. Shaban and S. U. M. Khan, "Carbon Modified (CM)n- $\mathrm{TiO}_{2}$ Thin Films for Efficient Water Splitting to $\mathrm{H}_{2}$ and $\mathrm{O}_{2}$ under Xenon Lamp Light and Natural Sunlight Illuminations," Journal of Solid State Electrochemistry, Vol. 13, No. 7, 2009, pp. 1025-1036.

[8] Y. A. Shaban and S. U. M. Khan, "Efficient Photoelectrochemical Splitting of Water to $\mathrm{H}_{2}$ and $\mathrm{O}_{2}$ at Nanocrystalline Carbon Modified (CM)-n- $-\mathrm{TiO}_{2}$ and (CM)-n- $\mathrm{Fe}_{2} \mathrm{O}_{3}$ Thin Films," International Journal of Nanotechnology, Vol. 7, No. 1, 2010, pp. 69-98. doi:10.1504/IJNT.2010.029549

[9] D. W. Chen and A. K. Ray, "Photocatalytic Kinetics of Phenol and Its Derivatives over UV Irradiated $\mathrm{TiO}_{2}$, , Applied Catalysis B: Environmental, Vol. 23, No. 2-3, 1999, pp. 143-157. doi:10.1016/S0926-3373(99)00068-5

[10] C. Burda, Y. Lou, X. Chen, A. C. S. Samia, J. Stout and J. L. Gole, "Enhanced Nitrogen Doping in $\mathrm{TiO}_{2}$ Nanoparticles," Nano Letters, Vol. 3, No. 8, 2003, pp. 1049-1051. doi:10.1021/n1034332o

[11] T. Oppenlander, "Photochemical Purification of Water and Air," Wiley-VCH, Weinheim, 2003.

[12] A. A. C. Magalhães, D. L. Nunes, P. A. Robles-Dutenhefner and E. M. B. De Sousa, "Catalytic Activity of Porous $\mathrm{TiO}_{2}$ Obtained by Sol-Gel Process in the Degradation of Phenol," Journal of Non-Crystalline Solids, Vol. 348, No. 12, 2004, pp. 185-189.

[13] S. Parsons, "Advanced Oxidation Processes for Water and Wastewater Treatment," IWA Publishing, Cornwall, 2004.

[14] R. M. Mohamed, A. A. Ismail, I. Othman and I. A. Ibrahim, "Preparation of $\mathrm{TiO}_{2}-\mathrm{ZSM}-5$ zeolite for Photodegradation of EDTA," Journal of Molecular Catalysis A: Chemical, Vol. 238, No. 1-2, 2005, pp. 151-157. doi:10.1016/j.molcata.2005.05.023

[15] K. Demeestere, J. Dewulf, T. Ohno, P. H. Salgado and H. Van Langenhove, "Visible Light Mediated Photocatalytic 
Degradation of Gaseous Trichloroethylene and Dimethyl Sulfide on Modified Titanium Dioxide," Applied Catalysis B: Environmental, Vol. 61, No. 1-2, 2005, pp. 140149. doi:10.1016/j.apcatb.2005.04.017

[16] H. Park and W. Choi, "Photocatalytic Reactivities of Nafion-Coated $\mathrm{TiO}_{2}$ for the Degradation of Charged Organic Compounds under UV or Visible Light," The Journal of Physical Chemistry B, Vol. 109, No. 23, 2005, pp. 11667 11674. doi:10.1021/jp051222s

[17] C. Xu, R. Killmeyer, M. L. Gray and S. U. M. Khan, "Photocatalytic Effect of Carbon-Modified n- $\mathrm{TiO}_{2}$ Nanoparticles under Visible Light Illumination," Applied Catalysis B: Environmental, Vol. 64, No. 3-4, 2006, pp. 312-317. doi:10.1016/j.apcatb.2005.11.008

[18] Y. A. Shaban, M. A. El Sayed, A. A. El Maradny, R. Kh. Al Farawati and M. I. Al Zobidi, "Photocatalytic Degradation of Phenol In Natural Seawater Using Visible Light Active Carbon Modified (CM)-n- $\mathrm{TiO}_{2}$ Nanoparticles under UV Light and Natural Sunlight Illuminations," Chemosphere, Vol. 91, No. 3, 2013, pp. 307-313. doi:10.1016/j.chemosphere.2012.11.035

[19] W. Choi, A. Termin and M. R. Hoffman, "The Role of Metal Ion Dopants in Quantum Sized $\mathrm{TiO}_{2}$ : Correlation between Photoreactivity and Charge Carrier Recombination Dynamics," Journal of Physical Chemistry, Vol. 98, No. 51, 1994, pp. 13669-13679. doi:10.1021/j100102a038

[20] M. Anpo, "Photocatalysis on Titanium Oxide Catalysts: Approaches in Achieving Highly Efficient Reactions and Realizing the Use of Visible Light," Catalysis Surveys from Japan, Vol. 1, No. 2, 1997, pp. 169-179. doi:10.1023/A:1019024913274

[21] R. Asahi, T. Morikawa, T. Ohwaki, K. Aoki and Y. Taga, "Visible-Light Photocatalysis in Nitrogen-Doped Titanium Oxides," Science, Vol. 293, No. 5528, 2001, pp. 269-271. doi:10.1126/science.1061051

[22] Y. C. Hong, C. U. Bang, D. H. Shin and H. S. Uhm, "Band Gap Narrowing of $\mathrm{TiO}_{2}$ by Nitrogen Doping in Atmospheric Microwave Plasma," Chemical Physics Letters, Vol. 413, No. 4-6, 2005, pp. 454-457. doi:10.1016/j.cplett.2005.08.027

[23] T. Umebayashi, T. Yamaki, H. Itoh and K. Asai, "Band Gap Narrowing of Titanium Dioxide by Sulfur Doping," Applied Physics Letters, Vol. 81, No. 3, 2002, pp. 454456. doi:10.1063/1.1493647

[24] M. R. Hoffmann, S. T. Martin, W. Choi and D. W. Bahnemann, "Environmental Applications of Semiconductor Photocatalysis," Chemical Reviews, Vol. 95, No. 1, 1995, pp. 69-96. doi:10.1021/cr00033a004

[25] C. S. Turchi and D. F. Ollis, "Photocatalytic Degradation of Organic Water Contamination: Mechanisms Involving Hydroxyl Radical Attack," Journal of Catalysis, Vol. 122, No. 1, 1990, pp. 178-192. doi:10.1016/0021-9517(90)90269-P

[26] J. R. Bolton, "Solar Photoproduction of Hydrogen: A Review," Solar Energy, Vol. 57, No. 1, 1996, pp. 37-50. doi:10.1016/0038-092X(96)00032-1

[27] Y. Li, G. Lu and S. Li, "Photocatalytic Hydrogen Generation and Decomposition of Oxalic Acid over Platinized $\mathrm{TiO}_{2}$," Applied Catalysis A: General, Vol. 214, No. 2,
2001, pp. 179-185. doi:10.1016/S0926-860X(01)00491-4

[28] C. W. King and M. E. Webber, "The Water Intensity of the Plugged-In Automotive Economy," Environmental Science and Technology, Vol. 42, No. 12, 2008, pp. 43054311.

[29] M. C. Lu, G. D. Roam, J. N. Chen and C. P. Huang, "Factors Affecting the Photocatalytic Degradation of Dichlorovos over Titanium Dioxide Supported on Glass," Journal of Photochemistry and Photobiology A: Chemistry, Vol. 76, No. 1-2, 1993, pp. 103-109. doi:10.1016/1010-6030(93)80180-H

[30] W. Z. Tang and C. P. Huang, "Photocatalyzed Oxidation Pathways of 2,4-Dichlorophenol by CdS in Basic and Acidic Aqueous Solutions," Water Research, Vol. 29, No. 2, 1995, pp. 745-756. doi:10.1016/0043-1354(94)00151-V

[31] M. Bekbolet and I. Balcioglu, "Photocatalytic Degradation Kinetics of Humic Acid in Aqueous $\mathrm{TiO}_{2}$ Dispersions: The Influence of Hydrogen Peroxide and Bicarbonate Ion," Water Science and Technology, Vol. 34, No. 9, 1996, pp. 73-80. doi:10.1016/S0273-1223(96)00789-5

[32] F. Akbal and A. N. Onar, "Photocatalytic Degradation of Phenol," Environmental Monitoring and Assessment, Vol. 83, No. 3, 2003, pp. 295-302. doi:10.1023/A:1022666322436

[33] R. Wang, D. Ren, S. Xia, Y. Zhang and J. Zhao, "Photocatalytic Degradation of Bisphenol A (BPA) Using Immobilized $\mathrm{TiO}_{2}$ and UV Illumination in a Horizontal Circulating Bed Photocatalytic Reactor (HCBPR)," Journal of Hazardous Materials, Vol. 169, No. 1-3, 2009, pp. 926-932. doi:10.1016/j.jhazmat.2009.04.036

[34] M. L. Chin, A. R. Mohamed and S. Bhatia, "Performance of Photocatalytic Reactors Using Immobilized $\mathrm{TiO}_{2}$ Film for the Degradation of Phenol and Methylene Blue Dye Present in Water Stream," Chemosphere, Vol. 57, No. 7, 2004, pp. 547-554. doi:10.1016/j.chemosphere.2004.07.011

[35] S. Merabet, A. Bouzaza and D. Wolbert, "Photocatalytic Degradation of Indole in a Circulating Upflow Reactor by $\mathrm{UV} / \mathrm{TiO}_{2}$ Process-Influence of Some Operating $\mathrm{Pa}$ rameters," Journal of Hazardous Materials, Vol. 166, No. 2-3, 2009, pp. 1244-1249. doi:10.1016/j.jhazmat.2008.12.047

[36] R. Jain and M. Shrivastava, "Photocatalytic Removal of Hazardous Dye Cyanosine from Industrial Waste Using Titanium Dioxide," Journal of Hazardous Materials, Vol. 152, No. 1, 2008, pp. 216-220. doi:10.1016/j.jhazmat.2007.06.119

[37] S. Ahmed, M. G. Rasul, W. N. Martens, R. Brown and M. A. Hashib, "Heterogeneous Photocatalytic Degradation of Phenols in Wastewater: A Review on Current Status and Developments," Desalination, Vol. 261, No. 1-2, 2010, pp. 3-18. doi:10.1016/j.desal.2010.04.062

[38] A. V. Petukhov, "Effect of Molecular Mobility on Kinetics of an Electrochemical Langmuir-Hinshelwood Reaction," Chemical Physics Letters, Vol. 277, No. 5, 1997, pp. 539-544. doi:10.1016/S0009-2614(97)00916-0

[39] K. H. Wang, Y. H. Hsieh and L. J. Chen, "The Heterogeneous Photocatalytic Degradation, Intermediates and Mi- 
neralization for the Aqueous Solution of Cresols and Nitrophenols," Journal of Hazardous Materials, Vol. 59, No. 2-3, 1998, pp. 251-260. doi:10.1016/S0304-3894(97)00151-9

[40] B. Bayarri, J. Gimenez, D. Curco and S. Esplugas, "Photocatalytic Degradation of 2,4-Dichlorophenol by $\mathrm{TiO}_{2} /$ UV: Kinetics, Actinometries and Models," Catalysis To- day, Vol. 101, No. 3-4, 2005, pp. 227-236. doi:10.1016/j.cattod.2005.03.019

[41] E. Kusvuran, A. Samil, O. M. Atanur and O. Erbatur, "Photocatalytic Degradation Kinetics of di- and Tri-Substituted Phenolic Compound in Aqueous Solution by $\mathrm{TiO}_{2} /$ UV," Applied Catalysis B: Environmental, Vol. 58, No. 3-4, 2005, pp. 211-216. doi:10.1016/j.apcatb.2004.11.023 